\title{
A DEFESA DO CONSUMIDOR E OS LIMITES ÉTICOS/NORMATIVOS ÀS PUBLICIDADES PAGAS (E DISFARÇADAS) EM BLOGS, SITES E APLICATIVOS DE INTERNET
}

\author{
Adeneele Garcia Carneiro* \\ Rogério Vinícius dos Santos*
}

\section{RESUMO}

O trabalho objetiva analisar a interação entre Direito, publicidade e jornalismo na contemporaneidade, considerando o contexto tecnológico, a fim de verificar a publicidade veiculada virtualmente em blogs, websites e instagram, sob a ótica do sistema de referência de Niklas Luhmann denominado Teoria dos Sistemas e na teoria da complexidade de Edgar Morin, para compreender a articulação das relações que permeiam a sociedade, a realidade conjuntural a que se faz menção à temática, e responder ao questionamento: quais os mecanismo de efetividade para atingir os fins éticos normativos do exercício da atividade publicitária realizadas pelas referidas vias, considerando a interdisciplinaridade apresentada?

PALAVRAS-CHAVE: Direito; Publicidade digital; Ética; Tecnologia; Teoria dos Sistemas

\section{THE CONSUMER DEFENSE AND THE ETHICAL / REGULATORY LIMITS ON PAY (AND DISGUISED) ADVERTISING IN BLOGS, SITES AND INTERNET APPLICATIONS}

\begin{abstract}
The objective of this work is to analyze the interaction between Law, advertising and journalism in contemporary times, considering the technological context, analyzing the publicity transmitted virtually in blogs, websites and instagram, under the Niklas Luhmann reference system called Systems Theory and in theory of the complexity of Edgar Morin, to understand the articulation of the relations that permeate society, the conjunctural reality to which the theme is mentioned, and answer: what are the mechanisms of effectiveness to achieve the normative ethical purposes of the exercise of the advertising activity carried out by the said routes, considering the interdisciplinarity presented?
\end{abstract}

KEYWORDS: Law; Digital advertising; Ethic; Technology; Systems Theory

\section{INTRODUÇÃO}

Para se falar em sociedade e em suas inúmeras conexões, importante salientar a correlação entre diversas áreas que permeiam a vida humana, a comunicação, o consumo, a regulação social. As interações ínsitas do seio social são permeadas por diversas áreas dos

\footnotetext{
* Graduada em Direito pela UNIC. Graduada em Psicologia pela UFMT. Mestre e Doutoranda em Direito pela Universidade de Marília - UNIMAR.

E-mail.email@adeneele.com.

* Licenciado em Letras pela UNESP/IBILCE. Graduado em Direito pelo Centro Universitário de Rio Preto UNIRP. Mestrando em Direito pela Universidade de Marília - UNIMAR Email: rogerio@rvsantos.com.br
} 
saberes, dentre elas o Direito, a publicidade, o jornalismo e a tecnologia são enfoques importantes no contexto contemporâneo.

Considerando o modo de produção capitalista e as regras mercadológicas, as táticas que permeiam a corrida pelas transações econômicas, o uso das tecnologias para realização de publicidade é cada dia mais constante.

A crescente nesse mercado é notória, que segundo O IAB Brasil (Interactive Advertising Bureau), composta pela Associação de Mídia Interativa brasileira, houve um crescimento na publicidade virtual de aproximadamente $26 \%$ no ano de 2016 , totalizando a média de R \$11,8 bilhões, com expectativa de 15 bilhões para o ano de 2017.

Embora, a crescente tanto de investimento em publicidades digitais, como o avanço das próprias redes de contatos seja confirmada, importante se faz compreender as modalidades de publicidades veiculadas, sabe-se que a informação, a divulgação de produtos e serviços e o uso dessas ferramentas são lícitos e regulados eticamente, todavia, cabe verificar como essas práticas tem se consolidado.

Assim sendo, demonstrar a importância de uma essencial correlação interdisciplinar para garantir os direitos constitucionais de acesso à informação, de liberdade de expressão, de manifestação do pensamento, de livre concorrência e livre iniciativa, dentre outros que permeiam a publicidade digital, são mecanismos necessários para compreender a complexidade ínsita as relações advindas dessa prática.

Portanto, o objetivo da presente pesquisa consiste em compreender a conexão entre do tema a fim de responder o seguinte questionamento: quais seriam os mecanismos de efetividade para se atingir os fins éticos normativos do exercício da atividade publicitária realizadas pelas referidas vias, considerando a interdisciplinaridade apresentada?

Considerando a ordem normativa e sistemática do Direito, o presente estudo pautouse em um corte metodológico, para abordar, mais especificamente a correlação de direito, publicidade e jornalismo no contexto tecnológico, a contextualização dos sites, blogs e instagram, para que assim seja feito a análise das publicidades pagas e disfarçadas nessas redes, sob a ótica ética do jornalismo.

Para tanto, o estudo desenvolver-se-á com o amparo de material bibliográfico, por meio de averiguação de expressão instrumental, como análise e fichamento de material sobre o tema, e a apresentação do objeto da presente pesquisa dar-se-á mediante a adoção do procedimento dedutivo. 


\title{
1 A CORRELAÇÃO ENTRE DIREITO, PUBLICIDADE E JORNALISMO NO CONTEXTO DIGITAL
}

Para compreender os limites éticos e normativos das publicidades pagas e disfarçadas, disseminadas no ambiente virtual é importante compreender a comunicação entre diferentes sistemas, sendo eles o Direito, a publicidade e o jornalismo.

Assim sendo, importante fazer uma conexão entre essas áreas, considerando que o jornalismo e a publicidade na perspectiva aqui adotada, se apresentam normativamente pelos eixos de preceitos éticos que os norteiam, todavia, a essência legal se consolida pela subordinação ao Direito, certo que será tutelada pelos mecanismos e diretrizes legais que guiam o ordenamento jurídico.

Considerando que as relações entre essas áreas se materializa por meio da comunicação, entendida como o ato da compreensão interconexo entre os sistemas, o resultado da informação, do ato de se comunicar e do entendimento, que gera um processo de observação e controle próprio dos sistemas. Assim, de acordo com LUHMANN, 1995, p. 306, a função da Comunicação consiste em "tornar provável o altamente improvável: a autopoiesis do sistema de comunicação, denominada sociedade"

\begin{abstract}
(...) a comunicação tem a especificidade de poder articular-se, indistintamente, ao ato de comunicar, ou à informação: o próximo passo da comunicação poderia continuar o mesmo, em referência ao ato de comunicar ou à informação. Daí que na própria operação da comunicação esteja incorporada a autorreferência (referência à informação), bem como a heterorreferência (referência ao ato de comunicar). (LUHMANN, 1995, p. 93)
\end{abstract}

Ou seja, conhecimento só se forma, com a comunicação que surge com os ruídos que ocorrem no sistema, e produz energia para mantê-lo, só produz sentido se fechado, todavia aberto, para autoprodução.

Sabendo que o Direito regula a sociedade, portanto toda e qualquer atividade humana de algum modo está tutelada per si, tanto pelas leis que regulam especificamente determinadas condutas, quanto pela não proibição para tanto, assim sendo, toda e qualquer área do conhecimento se comunica com ele, ou seja, compartilham-se por meio das irradiações, já que dentro de sua autopoiese elas se autoproduzem, e são afetas pela sociedade.

A evolução jurídica, tem como característica a impossibilidade planificação e posteriormente o reconhecimento dos avanços, promove, portanto, a interação entre os 
indivíduos e o sistema como um todo, e os subsistemas que se permeiam e promovem a evolução.

Considerando o contexto contemporâneo, onde a tecnologia, a internet, a comunicação em massa, as garantias constitucionais de informação, de liberdade de expressão, de manifestação do pensamento, além proliferação da cultura consumerista, permeiam as relações humanas, em especial as publicitárias, não há que se falar em análise isolada dessas condutas.

Há que se compreender como já dito que a comunicação entre os sistemas é fundamental para que os acoplamentos estruturais. Pela teoria de LUHMANN (1995, p. 47 e 60), o direito é um sistema funcional que busca equilibrar e estabilizar as expectativas por meio das normas jurídicas, essa figura como um sistema social, o sistema jurídico, o código binário do lícito/ilícito, traduz a comunicação como elemento base deste, a evolução se dá a medida que a comunicação jurídica ocorre com a controvérsias, já que ele pode tanto sanar litígios, quanto criar novos questionamentos, com base no próprio elemento base, o direito.

A reprodução do sistema jurídico se consolida com as normas, como a Constituição, leis, atos, contratos e todos os programas deste sistema, assim, o direito transforma o sistema é normativamente fechado, todavia aberto, já que faz o acoplamento estrutural com outros sistemas, transformando a realidade e a si mesmo.

Assim sendo, verifica-se que não há que se falar em correlação transdisciplinar sem se ater a complexidade inerente a essas, portanto, como afirma Edgar Morin em sua teoria da complexidade, "é evidente que a ambição da complexidade é prestar contas das articulações entre disciplinas, entre categorias cognitivas e entre tipos de conhecimento. De fato, a aspiração à complexidade tende para o conhecimento multidimensional." (MORIN, 2013. p. 44)

Falando, portanto, dos diferentes sistemas sociais que analisaremos, importante se faz compreender os conceitos que os orienta, primeiramente, compreendemos a etimologia do termo publicidade, tem origem do latim "publicus", de público, no sentido de divulgação, propagação de informações ao acesso geral.

De acordo com BENJAMIN, (Revista de Direito do Consumidor, n. 9, p. 25-57), a publicidade é compreendida como "forma de comunicação social”, caracterizada por sua transmissão e conteúdo informativo, com a finalidade de difusão de atividade econômica.

Além disso, salienta-se que a publicidade se encontra de diferentes modos e veículos de informação em todo o mundo, claro que estamos falando do fenômeno, e não de um 


\section{A DEFESA DO CONSUMIDOR E OS LIMITES ÉTICOS/NORMATIVOS ÀS PUBLICIDADES PAGAS (E DISFARÇADAS) EM BLOGS, SITES E APLICATIVOS DE}

INTERNET

trabalho em si, consolidando-se, portanto, como um fenômeno transfronteiriço, principalmente com o advento da internet e o alcance desta.

Aspectos jurídicos, geográficos, políticos, culturais, étnicos e religiosos, devem ser considerados na prática da publicidade, certo que cabe a essa área fazer a conexão do anunciante ao consumidor, ou público alvo da informação.

A conectividade com a sociedade de consumo é notória, o que leva a publicidade a estar completamente ligada a um subsistema jurídico, mais especificamente o que tutela as relações consumeristas o direito do consumidor, já que as ofertas, comerciais massificados, emitidos por um sujeito identificado que paga por esses anúncios, sejam eles de produtos ou serviços, se utilizando de informações e persuasão, para alcançar o consumidor, são tutelados pelo referido microssistema.

Quando o direito veda a publicidade enganosa ou abusiva por exemplo, controla o marketing em todas as suas modalidades seja oral ou escrita, por meios de comunicação em massa ou não, por promoções audiovisuais, ilustrações que devem ser seguidas mesmo que realizada por websites, blogs, redes sociais, ou qual for o meio, está condicionando as ações dos sujeitos envolvidos.

Como já ressaltamos, na era da sofisticação tecnológica e da comunicação de massa, a mensagem publicitária, em definitivo, deixou de ser, na maior parte das hipóteses, veículo de informação. A função atual da publicidade, nos termos que vem sendo praticada, não é mais aquela de informar o consumidor, mas a de estimular e direcionar o consumo, promovendo o escoamento da produção (Guido Alpa, 1986, p. 124)

Cabe, portanto, ao direito, acompanhar as mudanças vertidas neste contexto e se comunicar com essas áreas, considerando toda complexidade que permeia essa relação, para que dos ruídos que surgem nessas novas modalidades, possa então, emitir novas respostas que permitam as atividades publicitárias possam ter as garantias que lhe são legalmente asseguradas, e que cumpram o papel a que se devem destinar.

Uma vez que, pela teoria sistêmica de Luhmann, o direito pode ser compreendido como um sistema social funcional, que busca equilibrar expectativas, essas, aliadas as normas jurídicas, que continuam estáveis mesmo ante possíveis violações, assim sendo, a comunicação firma o elemento padrão do direito como sistema social.

Havendo inconsistências o código de licitude será utilizado, buscando assim sanar litígios, todavia, essa comunicação pode ensejar novos conflitos que partem do próprio 
direito, essa dinamicidade é fundante para o alcance dos ideários do direito. Correlacionando com a publicidade e jornalismo contemporaneamente, ou seja, em um ambiente tecnológico, onde os ruídos aumentam a Constituição, figura como como mecanismo de autonomia operacional, de acoplamento estrutural, já que estamos falando de limites para o sistema jurídico, mesmo que sejam limites implícitos.

Quanto ao jornalismo, seu caráter social é notório, uma ciência que surge da apreensão da realidade, a partir de fenômenos jornalísticos, sociais, fatos o "produto do jornalismo, os "fatos jornalísticos", igualmente são fatos sociais só que mediados pelo trabalho dos jornalistas", o surgimento do fato "se estabelece como objetividade, algo externo ao sujeito". (PONTES, 2015)

Quando penso em jornalismo, aqui, penso em notícia, fatos. Não me passa pela cabeça a crônica. Não penso em nada que não tenha referência direta, indestrutível, no reconhecido, naquilo que ao menos mais de uma pessoa viu. Estamos no século XXI. Só posso, hoje, conceber o jornalismo assim - uma relação multilateral, no mínimo triangular. (AJZENBERG, 2002, pp. 53-54)

Considera-se, portanto, o jornalismo como esse trabalho intelectual de informar fatos, traduzir o sentido de uma proposição existente, no contexto de um evento por uma ação comunicativa, seja por qual via ela ocorrer, o trabalho jornalístico não está associado a uma só modalidade de envio da mensagem.

A essencialidade de informação, direito garantido constitucionalmente, aliados à liberdade de imprensa, de expressão, enseja a responsabilidade legal e respaldo jurídico de que qualquer violação a esses direitos, devem ter respaldo jurídico, ainda que principiológico.

A dinamicidade da publicidade, do direito, do jornalismo e da tecnologia não estão desconectados, se comunicam à medida que todos lidam com condutas sociais que norteiam sua atuação, e são modificados por elas, nessas conexões, insurgem novos direitos, táticas publicitárias e jornalísticas, bem como afetam a sociedade em si, à medida que impõe regras e modelos de conduta.

\section{2 Às PUbliCIDAdeS PAgas (E DISFARÇADAS) EM BLOGS, SITES E ISTAGRAM}

A estrutura social se modifica com celeridade, as transformações se dão em todos os setores da sociedade, tanto econômico, quanto social, político e jurídico, as referidas 


\section{A DEFESA DO CONSUMIDOR E OS LIMITES ÉTICOS/NORMATIVOS ÀS PUBLICIDADES PAGAS (E DISFARÇADAS) EM BLOGS, SITES E APLICATIVOS DE}

INTERNET

mudanças ocorrem com passagem de eras, marcadas por alterações tecnológicas e avanços operacionais que condicionam as condutas dos sujeitos.

Com o advento da internet o comportamento humano foi consideravelmente afetado, consequentemente toda e qualquer interação humana está permeada pelo uso das tecnologias, através da grande rede da internet as redes sociais, sites e os meios de comunicação digital se tornaram eventos cada vez mais presentes no cotidiano dos sujeitos e seu espantoso crescimento e a difusão em todo o mundo faz com que não possamos ignorar a reflexão sobre as publicidades praticadas por esse meio, essa preocupação se torna ainda mais necessária quando discutimos o papel da informação e liberdade de expressão como direito fundamental.

Em razão dessa difusão da internet, a publicidade tomou rumos ainda maiores, já que diferente das outras mídias, a possibilidade de interação, integração de recursos e públicos, maior alcance com menor investimento, houve maior propagação de técnicas de divulgação competitivas, em especial o uso de mídias sociais, se apresentam como importante canal de relacionamento e captação de potenciais consumidores.

Há diferentes modalidades legais de publicidade em Blogs, sites e Instagram, é possível vender espaços específicos para publicidade, há os publieditoriais que são a comercialização de espaços reservados e vendidos para que empresas publiquem editoriais, matérias de seu interesse, considerando a autoria do editor da empresa, estando portanto, o anúncio da fonte, os e-mails marketing são também opções para os detentores de sites e blogs, desde que os contatos advenham de sua lista de e-mails para não ser considerado spam.

As conexões entre todas essas redes são imprescindíveis para o sucesso do empreendimento digital, seja de conta em redes sociais, seja de sites ou blogs, normalmente há contas em todas as modalidades para se alcançar maior número de usuários, que passam a ser tidos como consumidores por empresas que se interessam em anunciar sua marca por essas vias.

A publicidade digital não é vedada, ocorre que há práticas publicitárias em dissonância com a legislação, e com o código de ética da própria área, um exemplo plausível das publicidades pagas e disfarçadas em redes sociais, websites e blogs, além de outros tipos de rede de contatos, também denominada publicidade velada, denominada aquela em que o detentor da conta recebe para fazer propaganda disfarçada de produtos e vantagens para promover a marca pagante, sem informar seus seguidores do referido patrocínio, passando a impressão de ser apenas um usuário satisfeito que despretensiosamente elogia os produtos 
e/ou serviços.

Considerando que publicidade consiste em "conceito universalmente, acatado, como o conjunto de meios destinados a informar o público e a convencê-lo a adquirir um bem ou serviço." (LOPES, RDC, vol.1., p.151)

Assim sendo, é notório que toda publicidade é de algum modo pretenciosa, não uma escusa em dever ser clara em seu propósito, já que a comunicação não é neutra o público atingido deve ter consciência dessa tática para que possa livremente optar sem necessariamente ser induzido erroneamente a algo.

[...] quer parecer que a publicidade comercial tenha por principal característica a persuasão. É que a publicidade comercial, como ato de comunicação, está predisposta à realização de uma finalidade: a promoção do consumo. Nessa trilha o resultado pretendido é concretizado quando a mensagem incute no consumidor, direta ou indiretamente, o desejo de comprar. Exerce, pois, função empática, de fazer o consumidor aceitar o produto ou serviço. Para atingir essa meta, a linguagem publicitária, eminentemente persuasiva, utiliza a informação. Essa informação, no entanto, não é veiculada de maneira anódina, imparcial. Ao contrário, as características e demais aspectos do produto, objeto da informação, são manipulados. ("a verdade bem dita") ou, em outras palavras, operacionalizados à vista do fim que pretendem concretizar." (NUNES JÚNIOR, 2001. p.25-26) (grifo do autor)

Como aludido, no Código de Defesa do Consumidor em seu art. 36, prevê que "A publicidade deve ser veiculada de tal forma que o consumidor, fácil e imediatamente, a identifique como tal. " Inclusive em seu parágrafo único enseja a obrigação do difusor da mensagem em seu parágrafo único, ao afirmar que "O fornecedor, na publicidade de seus produtos ou serviços, manterá, em seu poder, para informação dos legítimos interessados, os dados fáticos, técnicos e científicos que dão sustentação à mensagem. ”

Considerando a vastidão de mecanismos precursores dessas mensagens e das novas táticas de publicidade advindas da difusão digital, precisa-se contextualizar a dimensão das ferramentas tecnológicas, sabe-se que no Brasil, segundo pesquisa da a agência de marketing social We Are Social, no relatório Digital, Social e Mobile de 2015, que mostrou estatísticas completas de uso de internet no ferido ano, demonstrou que só no Brasil são 204 milhões de indivíduo, destes, 54\% são usuários ativos de internet equivalente a 110 milhões de usuários, desses 96 milhões estão conectados a uma rede social. (WEARESOCIAL. digital-socialmobile-in-2015. Disponível em: <https://pt.slideshare.net/wearesocialsg/digital-social-mobilein-2015.> Acesso em: 26 de junho de 2017) 


\section{A DEFESA DO CONSUMIDOR E OS LIMITES ÉTICOS/NORMATIVOS ÀS PUBLICIDADES PAGAS (E DISFARÇADAS) EM BLOGS, SITES E APLICATIVOS DE}

INTERNET

Foi possível verificar ainda que temos mais números de celulares que pessoas no país, cerca de 276 milhões e desses, 79 milhões estão ativos e 78 milhões deles se conectam-se socialmente por meio do seu mobile, ressaltando que todos esses índices demonstraram crescimento em relação a 2014, ano anterior a pesquisa.

O instagram encontra-se entre uma das principais redes sociais mais acessadas do mundo, no Brasil se encontra como a $5^{\circ}$ ferramenta mais utilizada para conectividade, a rede criada em 2010, no mesmo ano conseguiu mais de 1 milhão de usuários no mundo, em 2016 alcançou o feito de 600 milhões e em 26 de maio de 2017 anunciou o feito de 700 milhões de usuários.

Apontamentos da SumAll e socialbakers empresas que comercializam internacionalmente ferramentas métricas de uso do aplicativos para redes sociais para publicidade por empresas, demonstra que o engajamento dos seguidores no Instagram é muito superior ao que de outras redes sociais, justamente por conta do perfil do público, menores informações aleatórias e maior credibilidade das publicações.

Verifica-se, portanto, um vasto mercado publicitário de rápido alcance, salienta-se ainda que o número de websites no Brasil é muito grande, e em 2016 chegou próximo a 1 bilhão, considerando que há uma rotatividade muito grande e que muitos dos sites.

Quanto aos blogs, conforme resultados de uma pesquisa realizada pela empresa de análise de tráfego online chamada Sysomos em 2010 o Brasil apresenta-se como o $4^{\circ}$ país do mundo em número de blogueiros, considerando o perfil do público de pessoas entre 21e 35 anos e com aproximadamente 50\% de público feminino. (Inside Blogger Demographics. Disponível em: <https://sysomos.com/reports/blogger-demographics/> Acesso em 26 de junho de 2017)

Portanto, verifica-se que as vias de difusão de informações, publicidade e captação de potenciais consumidores é realmente notória quando se fala em mecanismos digitais, ocorre que as regras legais que norteiam a publicidade continuam sendo as mesmas, independente do meio de propagação, certo que a proteção do consumidor contra condutas abusivas perfaz importante mecanismo de tutela jurídica.

Como já aludido, a publicidade velada é a prática mais corriqueira em sites, blogs e redes sociais, já que para estabelecer um nível de confiabilidade com os seguidores, ou seja, com o público atingido, a naturalidade e espontaneidade na divulgação de produtos e serviços, perfazem táticas de marketing para se alcançar a finalidade de consumo. 
Na tentativa de resolução de publicidades desse cunho, o Código de Defesa do Consumidor - CDC, aduz em seu art. 37 dispõe que:

Art. 37. É proibida toda publicidade enganosa ou abusiva.

$\S 1^{\circ}$ É enganosa qualquer modalidade de informação ou comunicação de caráter publicitário, inteira ou parcialmente falsa, ou, por qualquer outro modo, mesmo por omissão, capaz de induzir em erro o consumidor a respeito da natureza, características, qualidade, quantidade, propriedades, origem, preço e quaisquer outros dados sobre produtos e serviços.

$\S 2^{\circ}$ É abusiva, dentre outras a publicidade discriminatória de qualquer natureza, a que incite à violência, explore o medo ou a superstição, se aproveite da deficiência de julgamento e experiência da criança, desrespeita valores ambientais, ou que seja capaz de induzir o consumidor a se comportar de forma prejudicial ou perigosa à sua saúde ou segurança.

$\S 3^{\circ}$ Para os efeitos deste código, a publicidade é enganosa por omissão quando deixar de informar sobre dado essencial do produto ou serviço.

Salienta-se ainda que a Lei 4680 de junho de 1965, que dispõe sobre o exercício da profissão de Publicitário e de Agenciador de Propaganda e dá outras providências, prevê em seus respectivos dispositivos que os veículos de divulgação, amparados pela respectiva norma são quaisquer meios de comunicação visual ou auditiva capazes de transmitir mensagens de propaganda ao público, desde que reconhecidos pelas entidades e órgãos de classe e sindicatos publicitários, estando portanto a publicidade digital amparada. Em seu art. $5^{\circ}$ "Compreende-se por propaganda qualquer forma remunerada de difusão de ideias, mercadorias ou serviços, por parte de um anunciante identificado. ”

O sistema de regulamentação da publicidade pode ser caracterizado por ser misto, ou desconcentrado já que tanto o Estado quanto entidades publicitárias agem nesse sentido, como por exemplo o Conselho Brasileiro de Auto-Regulamentação Publicitária - CONAR, e o Código Brasileiro de Auto-regulamentação Publicitária, que tem por base a as diretrizes da legislação publicitária do País, especialmente capituladas na Lei $n^{\circ} 4.680$, de 18 de junho de 1965, e no Decreto ${ }^{\circ} 57.690$, de $1^{\circ}$ de fevereiro de 1966;

Assim sendo, verifica-se que há mecanismos para compreender a interconexão social, tecnológica, econômica, publicitária e jurídica das práticas suscitadas, considerando a complexidade já aduzida, importante verificar que não há que se falar em novas normas jurídicas, mas a comunicação entre as referias áreas para aplicabilidade das previsões já existentes, hermeneuticamente para estar em consonância com as demandas contemporâneas.

3 PUblicidade digital: UMA ANÁlise A PARTIR do CONCEITO DE 


\section{JORNALISMO}

A veiculação de notícias, informações, ofertas, brindes, anúncios diversos sobre produtos e serviços perfazem atividades corriqueiras na área da publicidade propaganda, sendo estas, disseminadas por diferentes veículos de comunicação. Sabe-se que com o advento da internet, cada dia mais, se torna mais barato, prático, rápido e com maior alcance, gerando maior lucro para os anunciantes.

Para análise dessa publicidade digital sob a ótica do jornalismo importante compreender que "jornalismo é a informação de fatos correntes, devidamente interpretados e transmitidos periodicamente à sociedade, com o objetivo de difundir conhecimentos e orientar a opinião pública, no sentido de promover o bem comum” (BELTRÃO, 1992, p. 67)

Portanto, a atividade jornalística se realiza em toda e qualquer forma de propagação de informações, registro de fatos, notícias que tenham clareza e fidedignidade para um público, uma vez que, a responsabilidade para com a divulgação é imprescindível para um coerente exercício da atividade profissional.

Considerando a conexão com a publicidade digital em especial ocorrida por meio de blogs, sites e instagram, compreende-se que embora não sejam atividades jornalísticas em sentido estrito, ao assumir o papel de difusor de informações, o detentor dessas vias de transmissão, estão sujeitos ao comprometimento com suas publicações.

Em especial, quando a espontaneidade é pressuposta na divulgação de produto ou serviço, subtendendo que não há patrocínio para divulgação daquela experiência com aquele determinado material, há que se compreender que os conhecimentos ali prestados possuem cunho informativo, estando, portanto, correlacionado com a ideia do processo comunicativo que o jornalismo pressupõe.

Considerando a influência que o processo comunicativo gera nos sujeitos, principalmente quando se fala em massas, é importante compreender a magnitude dessas divulgações.

(...) o desenvolvimento dos meios de comunicação é, em sentido fundamental, uma reelaboração do caráter simbólico da vida social, uma reorganização dos meios pelos quais a informação e o conteúdo simbólico são produzidos e intercambiados no mundo social e uma reestruturação dos meios pelos quais os indivíduos se relacionam entre si. (THOMPSON, 1998. p. 19) 
Verifica-se assim que as mudanças no modo de comunicação, impacta não só no modo de divulgação da informação, mas no meio de recebimento desta, enseja uma releitura tática de produção de transmissão eficaz, seja para informar, seja para anunciar algo.

A comunicação de massa implica a mercantilização das formas simbólicas no sentido de que os objetos produzidos pelas instituições da mídia passam por um processo de valorização econômica. [...] A mercantilização de alguns impressos, como livros e panfletos, depende quase inteiramente da capacidade de produzir e vender as múltiplas cópias da obra. Outros impressos (jornais, por exemplo) combinam este tipo de valorização com outros, como a capacidade de vender o espaço de propaganda. No caso das transmissões de rádio e televisão, a venda do tempo de propaganda aos anunciantes tem sido fundamental importância, em alguns contextos nacionais, para a valorização econômica. (THOMPSON, 1998. p. 33)

A conexão entre publicidade e jornalismo enseja justamente nessa capacidade comunicativa entre esses sistemas e ambos se relacionam com o direito, quando estão tutelados por normas do ordenamento jurídico que orientam sua realização, o que nos leva a teoria de Luhmann, quando embora o sistema seja fechado em sua área os ruídos da comunicação entre os sistemas que é aberta, gera o acoplamento estrutural pela relação entre o sistema e o entorno, gerando a operação genuinamente social, quando essas ações se correlacionam por meio do sentido.

Considerando essa interconexão, salienta-se que como estamos falando para o jurídico de direito à informação, para a publicidade a propagação desta e para o jornalismo a direito de informar, importante verificar os preceitos éticos que norteia essa atividade previstos no Código de Ética dos Jornalistas Brasileiros, que preceitua:

Art. $2^{\circ}$ Como o acesso à informação de relevante interesse público é um direito fundamental, os jornalistas não podem admitir que ele seja impedido por nenhum tipo de interesse, razão por que:

I - a divulgação da informação precisa e correta é dever dos meios de comunicação e deve ser cumprida independentemente de sua natureza jurídica - se pública, estatal ou privada - e da linha política de seus proprietários e/ou diretores.

II - a produção e a divulgação da informação devem se pautar pela veracidade dos fatos e ter por finalidade o interesse público;

III - a liberdade de imprensa, direito e pressuposto do exercício do jornalismo, implica compromisso com a responsabilidade social inerente à profissão; [...] 
A maior implicação evidenciada tange a responsabilidade na tarefa essencial de construção social por meio das informações transmitidas, fazendo com que o blogger, agencias, empresários ou qualquer famoso da internet, tenha que ter compromisso ético e legal de ser claro ao público.

Os influenciadores digitais não podem representar para persuadir, interpretando como artistas despretensiosos, sem fazer menção a um informe publicitário com as devidas implicações que esta enseja, o comprometimento ético é fundamental para credibilidade da rede e consequentemente daquele canal, como prevê o referido código e ética em seu Art. 10. “A opinião manifestada em meios de informação deve ser exercida com responsabilidade. "

Uma das obrigações éticas dos jornalistas é o dever de Art.12 "IV - informar claramente à sociedade quando suas matérias tiverem caráter publicitário ou decorrerem de patrocínios ou promoções;" portanto as publicidades pagas e disfarçadas ferem gravemente o código de ética e consequente norma legal já que se equipara a publicidade enganosa.

Caso seja apenas para informar uma experiência os influenciadores digitais podem fazer o uso e utilizar por exemplo um presskit, que consiste em uma observação no ato da postagem informando que o referido produto ou serviço, pertence a determinada marca e que ele foi adquirido ou ganhando da referida empresa, e que aquela publicação traduz uma opinião pessoal que se deu pela experiência de uso.

Todavia, caso a publicidade foi patrocinada e não pode ser divulgada aquela prática, ou seja a técnica de "merchandising" disfarçado, importante que o contratado compreenda que além de antiético essa prática é coibida perante o Código de Defesa do Consumidor, que prevê a identificação da propaganda como princípio basilar das relações consumeristas.

\section{CONCLUSÃO}

A proposta do presente trabalho foi responder ao seguinte questionamento: quais seriam os mecanismos de efetividade para se atingir os fins éticos normativos do exercício da atividade publicitária realizadas pelas referidas vias, considerando a interdisciplinaridade apresentada?

Por todo exposto resta evidenciado que, a interconexão disciplinar se justifica pela comunicação entre os sistemas jurídico, publicitário e jornalístico à medida que se trata de 
direito à informação, propagação desta e o direito de informar.

As complexidades dessas interações se encontram-se nessa conexão dos direcionamentos para a atividade publicitária constantes em todos os sistemas, assim, legítimo se faz o referido exercício, desde que em consonância com os preceitos éticos e legais que o norteia.

Quanto as publicidades pagas e disfarçadas em blogs, sites e Instagram, sabe-se que essas atividades destoam das previsões éticas, do enfoque da informação, sabendo que com o uso da internet a propagação das informações tomam dimensões inimagináveis, assim sendo, considerando a informação como importante mecanismo de formação de opinião, de acesso a conhecimento, de credibilidade, perfaz essencial que esta seja transmitida em acordo com as diretrizes que orienta essa prática.

Assim sendo, a maior implicação tange a responsabilidade na tarefa essencial de construção social por meio das informações transmitidas, fazendo com que o blogger, agencias, empresários ou qualquer famoso da internet, tenha que ter compromisso ético e legal de ser claro ao público.

Considerando que os precursores dessas práticas, são influenciadores digitais que não podem representar para persuadir, interpretando como artistas despretensiosos, sem fazer menção a um informe publicitário com as devidas implicações que esta enseja, o comprometimento ético é fundamental para proteção do público atingido, considerando-os como consumidores, além de ser crucial para a credibilidade da rede e consequentemente daquele canal.

Verifica-se assim que as mudanças no modo de comunicação, impacta não só no modo de divulgação da informação, mas no meio de recebimento desta, enseja uma releitura tática de produção de transmissão eficaz, clara, precisa, ética e responsável, sendo, portanto, esses os requisitos primordiais e efetivos de uma publicidade digital ética.

\section{REFERÊNCIAS}

AJZENBERG, Bernardo. 2002. "Dois senhores". In: Gustavo de Castro \& Alex Galeno (orgs.), Jornalismo e literatura: a sedução da palavra. São Paulo: Escrituras.

BRASIL, LEI No 4.680/1965. Disponível em: <http://www.planalto.gov.br/ccivil_03/leis/L4680.htm> Acesso em: 27 de junho de 2017 


\section{A DEFESA DO CONSUMIDOR E OS LIMITES ÉTICOS/NORMATIVOS ÀS PUBLICIDADES PAGAS (E DISFARÇADAS) EM BLOGS, SITES E APLICATIVOS DE}

BRASIL. Constituição da República Federativa do Brasil. Disponível em:

<http://www.planalto.gov.br/ccivil_03/constituicao/constituicao.htm> Acesso em: 27 de junho de 2017

Lei $\mathrm{n}^{\circ}$ 8.078, de 11 de setembro de 1990: dispõe sobre a proteção do consumidor e dá outras providências. Disponível em: 〈http://www.planalto.gov.br/ccivil_03/leis/18078.htm>. Acesso em: 27 de junho de 2017

BELTRÃO, Luiz. Iniciação a filosofia do jornalismo. São Paulo, Edusp, 1992.

BENJAMIN, Antônio Herman de Vasconcellos e. O controle jurídico da publicidade. Revista de Direito do Consumidor, n. 9. Disponível em:

<http://bdjur.stj.jus.br//dspace/handle/2011/8981>. Acesso em: 26 jun. 2017.

Código de Ética dos Jornalistas Brasileiros. Federação Nacional dos Jornalistas. Disponível em: <http://fenaj.org.br/wp-content/uploads/2014/06/04-

codigo_de_etica_dos_jornalistas_brasileiros.pdf.> Acesso em 25 de jun. 2017.

GUIDO, Aldo. Diritto Privato dei Consumi, Bologna, il Mulino, 1986.

IAB- Investimento em publicidade digital no brasil. Disponível em: http://iabbrasil.net/assets/upload/boas_praticas/1490822463.pdf Acesso em: 26 de junho de 2017.

Inside Blogger Demographics. Disponível em: <https://sysomos.com/reports/bloggerdemographics/> Acesso em: 26 de junho de 2017.

LOPES, Maria Elizabete Vilaça. O consumidor e a publicidade, RDC, vol.1, São Paulo: Revista dos Tribunais, p.151.

LUHMANN, Niklas [1995]. Introdução à teoria dos sistemas: aulas publicadas por Javier Torres Nafarrate. Trad. de Ana Cristina Arantes Nasser. Petrópolis: Vozes, 2010.

LUHMANN, Niklas. Sociedade y sistema: laambición de lateoría,

MORIN, Edgar. A Via para o futuro da humanidade. Rio de Janeiro: Bertrand Brasil, 2013. 
NUNES JÚNIOR, Vidal Serrano. Publicidade comercial: proteção e limites na constituição de 1988, São Paulo: Juarez, 2001.

PONTES, Felipe Simão. GENRO FILHO, Adelmo Genro Filho e a Teoria do Jornalismo. Florianópolis: Insular, 2015.

THOMPSON, John B. A mídia e a modernidade: uma teoria social de mídia. Petrópolis, RJ: Vozes, 1998.

WEARESOCIAL. digital-social-mobile-in-2015.

Disponível em: <https://pt.slideshare.net/wearesocialsg/digital-social-mobile-in-2015.> Acesso em: 26 de junho de 2017. 